\title{
A LEITURA NOS ANOS INICIAIS DO ENSINO FUNDAMENTAL: percepções de professoras de escola da Rede Municipal de Ensino de João Pinheiro
}

\section{READING IN THE INITIAL YEARS OF FUNDAMENTAL EDUCATION: perceptions of school teachers From the Municipal Education Network of João Pinheiro.}

\section{Frânquia Rômia Bonfimm ${ }^{1}$ Idalberto José das Neves Júnior ${ }^{2}$ https://doi.org/10.29327/216986.1.1-9}

RESUMO: É através do hábito de ler que o aluno constrói seu conhecimento para a vida em sociedade. O objetivo deste artigo foi o de evidenciar a percepção docente a respeito da importância da leitura nos anos iniciais do ensino fundamental nas dimensões do uso dos recursos pedagógicos, dos métodos, a dinâmica das aulas e a aprendizagem dos estudantes. Com esse propósito, realizou-se a coleta de dados por meio de entrevistas realizadas no ano de 2017, com a participação de $10(\mathrm{dez})$ professoras, que lecionam em Escola da Rede Municipal de Ensino da cidade de João Pinheiro, estado de Minas Gerais (MG). Os principais resultados evidenciaram que a importância da leitura está na socialização dos estudantes, por meio da prática da leitura, em voz alta (individualmente ou em grupo), utilização de jogos e revistas, alavancada pelo interesse das crianças por meio de descobertas, gerando um aprendizado pela curiosidade e motivação.

Palavras chave: Leitura. Recursos Pedagógicos. Métodos.

ABSTRACT: It is through the habit of reading that the student builds his knowledge for life in society. The purpose of this article

\footnotetext{
1 Licenciada do curso de Pedagogia EAD da Faculdade do Noroeste de Minas - FINOM. E-mail: frankiaromia@bol.com.br

${ }^{2}$ Doutorado em Educação pela Universidade Católica de Brasília (UCB), Mestrado em Gestão do Conhecimento e Tecnologia da Informação pela UCB. Graduações em Ciências Contábeis e em Tecnologia em Processamento de Dados pela Associação Cultural e Educacional de Barretos. Professor da Universidade Católica de Brasília - UCB. http://lattes.cnpq.br/1719721445601505 E-mail: idalbertoneves@gmail.com
} 
was to highlight the teaching perception about the importance of reading in the early years of elementary school in the dimensions of the use of pedagogical resources, methods, the dynamics of classes and student learning. For this purpose, data collection was carried out through interviews carried out in 2017, with the participation of 10 (ten) teachers, who teach in a School of the Municipal Teaching Network in the city of João Pinheiro, state of Minas Gerais (MG). The main results showed that the importance of reading is in the socialization of students, through the practice of reading aloud (individually or in groups), using games and magazines, leveraged by the interest of children through discoveries, generating a learning by curiosity and motivation.

Keywords: Reading. Pedagogical Resources. Methods.

\section{Introdução}

A leitura nos anos iniciais do Ensino Fundamental prevalece desde o início dos tempos, como uma atividade de muita importância, pois é através do hábito de ler que o aluno constrói seu conhecimento para a vida em sociedade.

Para que realmente aconteça a aprendizagem da leitura, deve ser realizado um trabalho com os alunos priorizando essa tarefa de ensinar a ler como sendo principal. A leitura é muito importante para que todas as pessoas possam exercer seus direitos, possam trabalhar e participar da sociedade com cidadania, se informar e aprender coisas novas ao longo de toda a vida.

$\mathrm{Na}$ escola, crianças, desde os primeiros anos do Ensino Fundamental precisam ter contato diariamente com diferentes textos, ouvir histórias, observar adultos lendo e escrevendo. Precisam participar de uma rotina de trabalho variada e estimulante e, além disso, receber muito incentivo dos professores e da família para que, na idade adequada, aprendam a ler fluentemente.

Para garantir que todos os alunos aprendam, a escola precisa ter uma proposta pedagógica com orientações claras para a alfabetização inicial. É na proposta pedagógica que ficam definidos 
quais os objetivos para cada etapa, que tipo de atividade precisa ser realizado na sala de aula e na escola, como será a avaliação. Assim os professores planejam suas aulas, e percebem o resultado positivo de seu trabalho ao ver seu aluno sabendo ler e interpretando os textos.

Sabe-se que as crianças, nos primeiros anos do Ensino Fundamental, já têm maturidade suficiente e já estão preparadas para o processo de aquisição da leitura e participando assim do seu ensino e aprendizagem.

É mais significativo para a criança nesta fase sentir que é capaz de aprender, pois já reconhece que seu professor realiza com sua turma, um trabalho em sala de aula que lhe proporciona a capacidade de construir seu conhecimento da leitura. A maioria das crianças hoje já sai lendo da Educação infantil. Isso demonstra que a criança está madura para o aprendizado escolar. Ao chegar ao Ensino Fundamental vai encontrar um professor que já tem a ideia amadurecida para acolher e contribuir com a aprendizagem da leitura dos alunos e são capazes de identificar os fatores de risco e de proteção da prontidão escolar em crianças nos primeiros anos do ensino Fundamental.

Desde o nascimento, a criança inicia o aprendizado de leitura através da observação do seu próprio o corpo, realizando pequenos movimentos corporais, desenvolvendo a coordenação motora. Por isso, compreende-se que a história da leitura inicia ainda no aconchego do seu lar.

Assim, surge espontaneamente o começo de vida de relações com as pessoas em sua volta, o pensamento vai se desenvolvendo juntamente com a imaginação e criatividade. Brincando com as pessoas, a criança cria uma forma de se expressar, imitando tudo ao seu redor e fazendo uma leitura imaginativa cheia de fantasia.

No início do Ensino Fundamental, a criança já tem capacidade de localizar o lugar em que está e os caminhos por onde passa principalmente os que sejam mais próximos de sua casa, e isso é uma forma de leitura. Também já conhece letras símbolos e sons, portanto, o aluno já está pronto para a construção do conhecimento da leitura para a vida em sociedade. 
Vários estudos sobre a importância da leitura nos primeiros anos do Ensino Fundamental estão ligados a motivação da criança que deve ser feita pelo professor e pela família. Pois, para que a criança adquira o hábito de ler e a compreensão da leitura de mundo, se faz necessário o entendimento de vários processos que constituem a explicação das formas de decifrar símbolos e sons.

$\mathrm{O}$ processo de aquisição da leitura inicia-se pelo conhecimento das letras do alfabeto e ao juntá-las formando palavras, as crianças sentem-se motivadas a prosseguir e consegue à sua maneira, compreender o que está escrito.

Por isso, é importante ressaltar que a aquisição da leitura acontece através da interação, e da socialização com os outros e com o meio em que vive. É na família, o primeiro contato da criança com a leitura e ainda na infância, vai adquirindo mais conhecimentos se comunicando com outras pessoas, colegas de escola e também vão aos poucos se familiarizando com os livros e as escritas que estão por todas as ruas.

Como formulação do problema de pesquisa é possível delinear um ambiente educacional que nem sempre é favorável para a atividade de leitura nos anos iniciais, a exemplo da escassez de recursos didático-pedagógicos, a falta de investimentos na formação docente e uma remuneração que pouco representa a responsabilidade de formar cidadãos, que poderia comprometer o desenvolvimento social e inserção das crianças na sociedade. Porém, os docentes, em ideais de educadores formadores, buscam, de toda maneira, tornar a leitura nos anos iniciais do Ensino Fundamental uma possibilidade exitosa de desenvolvimento social e aprendizagem das crianças. Com isso, a questão central de pesquisa tem a pretensão de responder o seguinte questionamento: como esses professores percebem a importância da leitura nos anos iniciais do ensino fundamental nas dimensões do uso dos recursos pedagógicos, dos métodos, a dinâmica das aulas e da aprendizagem das crianças?

Com esse propósito, o objetivo deste estudo é evidenciar a percepção docente a respeito da importância da leitura nos anos iniciais do ensino fundamental nas dimensões do uso dos recursos 
pedagógicos, dos métodos, a dinâmica das aulas e a aprendizagem dos estudantes.

Para a realização deste estudo realizou-se pesquisa de campo, no ano de 2017, por meio de entrevistas, com a participação de 10 (dez) professoras da Escola da Rede Municipal da cidade de João Pinheiro, estado de Minas Gerais (MG), com a análise dessas entrevistas a partir dos preceitos teóricos de Ferreiro e Palácio (1990), Piaget (1978), Soares (1999), entre outros pesquisadores que estudaram a respeito da importância da leitura nos Anos Iniciais do Ensino Fundamental.

Este estudo é justificado diante da necessidade de conhecer um pouco mais sobre a importância da aquisição da leitura nos anos iniciais do Ensino Fundamental, contribuindo para que se possa planejar e realizar o processo de ensino e aprendizagem de qualidade e o aluno seja um cidadão crítico, criativo e conhecedor de seus direitos e deveres, para viver em comunidade se socializando e entendendo todas as escritas que circulam na sociedade.

A relevância desta pesquisa está em proporcionar aos profissionais da educação um repertório de reflexões sobre a importância da leitura nos anos iniciais do ensino fundamental nas dimensões do uso dos recursos pedagógicos, dos métodos, a dinâmica das aulas e a aprendizagem dos estudantes.

\section{Metodologia da Pesquisa}

A abordagem da questão de pesquisa é de natureza qualitativa, envolvendo a obtenção de dados descritivos sobre pessoas, lugares e processos interativos pelo contato direto do pesquisador com a situação estudada, procurando compreender os fenômenos segundo a perspectiva dos sujeitos, ou seja, dos participantes da situação em estudo (GADOTTI, 2001, p. 27).

A coleta de dados foi realizada por meio de pesquisa de campo, no ano de 2017, com a realização de entrevistas a 10 (dez) professoras que atuam nos anos iniciais de Escola da Rede Municipal da cidade de João Pinheiro, estado de Minas Gerais (MG). As entrevistas foram realizadas com o uso de um guia estruturado na 
forma de um questionário, contendo 8 (oito) perguntas, sendo 6 (seis) abertas e 2 (duas) fechadas.

Os dados dos questionários foram tabulados na forma de tabelas com a análise qualitativa dos achados da pesquisa a partir de autores que estudaram a importância da leitura nos Anos Iniciais do Ensino Fundamental, a exemplo de Ferreiro e Palácio (1990), Piaget (1978), Soares (1999). Os resultados desta pesquisa são apresentados a seguir.

\section{Descrição e Análise de Resultados}

Este tópico apresenta a descrição e a análise dos dados coletados de professoras, que possuem entre 25 e 30 anos de idade e que trabalham com alunos dos anos iniciais do Ensino Fundamental. A Tabela 1 apresenta as características docentes.

Tabela 1 - Características docentes

\begin{tabular}{|l|l|l|l|l|l|l|l|l|}
\hline Dados & Respostas & $\mathbf{\%}$ & $\begin{array}{l}\text { Resposta } \\
\text { s }\end{array}$ & $\mathbf{\%}$ & Respostas & $\mathbf{\%}$ & TT & $\mathbf{\%}$ \\
\hline Idade & $\begin{array}{l}\text { De 21 a 25 } \\
\text { anos }\end{array}$ & $20 \%$ & $\begin{array}{l}\text { De } 25 \text { a } \\
30 \text { anos }\end{array}$ & $\begin{array}{l}60 \\
\%\end{array}$ & $\begin{array}{l}\text { Acima de } \\
30 \text { anos }\end{array}$ & $\begin{array}{l}20 \\
\%\end{array}$ & 10 & $100 \%$ \\
\hline Formação & $50 \%$ & $\begin{array}{l}\text { Pós- } \\
\text { graduaçã } \\
\text { o em } \\
\text { psicopeda } \\
\text { gogia }\end{array}$ & $\begin{array}{l}30 \\
\%\end{array}$ & $\begin{array}{l}\text { Pós- } \\
\text { graduação } \\
\text { em } \\
\text { Português }\end{array}$ & $20 \%$ & 10 & $100 \%$ \\
\hline $\begin{array}{l}\text { Trabalha } \\
\text { com os } \\
\text { anos } \\
\text { iniciais }\end{array}$ & $\begin{array}{l}\text { Menos de 2 } \\
\text { anos }\end{array}$ & $20 \%$ & $\begin{array}{l}\text { Mais de 5 } \\
\text { anos }\end{array}$ & $\begin{array}{l}20 \\
\%\end{array}$ & $\begin{array}{l}\text { Menos de } \\
10 \text { anos }\end{array}$ & $60 \%$ & 10 & $100 \%$ \\
\hline
\end{tabular}

Fonte: dados coletados das professoras. (2017)

De acordo com a tabela acima, os professores têm idade entre 21 a 30 anos de idade, sendo $20 \%$ das professoras entrevistadas possuem de 21 a 25 anos de idade, $60 \%$ de 25 a 30 anos e $20 \%$ tem acima de 30 anos. Isso demonstra que esses professores são parte de uma classe de pessoas que trabalham com maturidade e conscientes da importância e responsabilidade de seu papel no processo de 
construção do conhecimento da leitura nos anos iniciais do Ensino Fundamental.

A idade e a formação acadêmica dos entrevistados, bem como a suas experiências pedagógicas estão representadas $50 \%$ formação acadêmica em Pedagogia, $30 \%$ pós-graduação em psicopedagogia e $20 \%$ pós-graduação em Português, sendo que $20 \%$ dessas profissionais trabalham há menos de 2 anos nos anos iniciais do Ensino Fundamental, 20\% há mais de 5 anos e $60 \%$ há menos de 10 anos.

Na Lei de Diretrizes e Bases da Educação Nacional LDB (Lei no . 9.394/96) alerta que todos os docentes deverão cursar o nível superior até o ano de 2020 e pode-se perceber que a formação acadêmica dos profissionais da Educação cresce cada vez mais, pois essa lei deixa claro a preocupação com todos os professores, principalmente aqueles que não tinham condições financeiras para se formar em um curso superior.

Da mesma forma, os professores se preocupam com sua formação, atendendo ao Plano Nacional de Educação (PNE), que tem como objetivo a formação superior a todos os profissionais da Educação Básica. (BRASIL, ANO 2015)

O tempo em que o professor trabalha no Ensino Fundamental também é importante, pois quanto maior for sua experiência maior também será seu aprendizado. Como disse o escritor Rosa (1956, p. 271), "Mestre não é quem sempre ensina, mas quem de repente aprende". O professor pode aprender com seus alunos, pois cada um na sua diversidade tem uma forma própria de construir seu conhecimento. Com relação a importância da leitura nos anos inicias do Ensino Fundamental, tem-se a Tabela 2.

Tabela 2 - Para você, qual a importância da leitura nos anos iniciais do Ensino fundamental?

\begin{tabular}{|c|c|c|}
\hline Alternativas & Prof. & $\mathbf{\%}$ \\
\hline $\begin{array}{c}\text { Para a construção do conhecimento para } \\
\text { leitura de mundo }\end{array}$ & 2 & $20 \%$ \\
\hline Para o desenvolvimento da socialização & 3 & $30 \%$ \\
\hline $\begin{array}{c}\text { Para usufruir de melhor qualidade de vida } \\
\text { em comunidade }\end{array}$ & 1 & $10 \%$ \\
\hline O desenvolvimento da escrita & 2 & $20 \%$ \\
\hline
\end{tabular}

Educação In Loco, v.01, n. 01, jan.-jun. 2020 - ISSN 2675-4304 


\begin{tabular}{|l|c|c|}
\hline A construção da língua falada & 2 & $20 \%$ \\
\hline TOTAL & $\mathbf{1 0}$ & $\mathbf{1 0 0 \%}$ \\
\hline
\end{tabular}

Fonte: dados coletados das professoras. (2017)

Foi questionado aos professores sobre a importância da leitura nos Anos Iniciais do Ensino Fundamental, sendo que 20\% dos mesmos acreditam que a leitura é importante para que a criança construa seu conhecimento de mundo, 30\% responderam que a leitura contribui para o desenvolvimento da socialização, 10\%dos entrevistados acham que a importância da leitura é importante para que a criança possa usufruir de melhor qualidade de vida em sociedade, $20 \%$ considera que a leitura promove o desenvolvimento da escrita e $20 \%$ responderam que a leitura contribui para a construção da língua falada.

Sabe-se que a leitura é primordial para a vida de todas as pessoas, a mesma faz parte do cotidiano de todos e por isso o trabalho de leitura com as crianças deve ser realizado sempre em todos os momentos.

A leitura contribui para ampliar a visão de mundo, estimular o desejo de outras leituras, exercitar a fantasia e a imaginação, compreender o funcionamento comunicativo da escrita, compreender a relação fala/ escrita, desenvolver estratégias de leitura, ampliar a familiaridade com os textos, desenvolver a capacidade de aprender, ampliar o repertório textual para a produção dos próprios textos, conhecer as especificidades dos diferentes tipos do texto, favorecer a aprendizagem das convenções da escrita, só para citar algumas possibilidades. (SMITH, 2006, p.36).

Ao conhecer a leitura, a criança desenvolve o gosto literário, aumentando assim o seu conhecimento e descobrindo novas "possibilidades" de aprendizagem, para que possam se socializarem e conviverem sendo respeitado e respeitando todas as pessoas da comunidade da qual faz parte. Além disso, a leitura constitui uma ferramenta preciosa para que as pessoas se comuniquem através da escrita e da fala. 
Em síntese, conquistam os melhores empregos e acabam usufruindo de melhor qualidade de vida. Nessas condições, pode-se dizer que em uma sociedade como a brasileira, na qual o acesso à cultura é ao mesmo tempo tão valorizado e tão restrito à pequena parte da população, a disseminação da prática da leitura na escola torna-se fundamental para a busca do exercício da cidadania e a conquista de uma realidade menos desigual, portanto, mais justa. Grosso modo, a capacidade de ler torna-se um importante instrumento de poder, pois cria espaço para que o cidadão tenha vez e voz: seja um sujeito que interaja na realidade em que vive.

Soares (1999, p. 19), defende que:

Em nossa cultura grafocêntrica, o acesso à leitura é considerado como intrinsecamente bom. Atribui-se à leitura um valor positivo absoluto: ela traria benefícios óbvios e indiscutíveis ao indivíduo e à sociedade forma de lazer e de prazer, de aquisição de conhecimentos e de enriquecimento cultural, de ampliação das condições de convívio social e de interação. Observa-se que a leitura abre um mundo de possibilidades àqueles que dominam essa competência, bem como praticamente exclui aquele que dela não sabe fazer uso, discriminando-o cultural, econômica e socialmente. Isso mostra que a leitura não é uma ação com fim em si mesma, mas uma capacidade, através da qual atingimos um determinado objetivo.

Portanto de acordo com autora citada acima a história da aquisição leitura por crianças nos primeiros anos do Ensino Fundamental é um processo básico, que acontece aos poucos e em um determinado momento passa a ser fluente no cotidiano da mesma, além disso, elas desenvolvem sua socialização e compartilham aquilo que já conseguem ler com seus colegas e os adultos que fazem parte da sua vida. No questionário, também foram feitas abertas e dentre elas indagou-se aos professores suas opiniões sobre a influência dos recursos pedagógicos para facilitar a aprendizagem, como apresentado na Tabela 3. 
Tabela 3 - Qual a sua opinião sobre a influência dos recursos pedagógicos para facilitar a aprendizagem?

\begin{tabular}{|c|c|c|}
\hline Respostas & Prof. & $\%$ \\
\hline $\begin{array}{l}\text { Para incentivar a prática da leitura aos } \\
\text { meus alunos costumo utilizar frequentemente a } \\
\text { literatura, pois as crianças se envolvem no mundo } \\
\text { literário, através dos sonhos e aventuras que } \\
\text { estimulam seu psicológico e consequentemente } \\
\text { despertando-a para o gosto de ler, ao invés de só } \\
\text { ouvir. }\end{array}$ & 4 & $40 \%$ \\
\hline $\begin{array}{l}\text { Os recursos pedagógicos motivam os } \\
\text { alunos a construírem seu conhecimento }\end{array}$ & 2 & $20 \%$ \\
\hline $\begin{array}{l}\text { São muito importantes na condução do } \\
\text { aprendizado do aluno. }\end{array}$ & 2 & $20 \%$ \\
\hline $\begin{array}{l}\text { São muito importantes pois influenciam } \\
\text { na socialização e na aprendizagem coletiva dos } \\
\text { alunos. }\end{array}$ & 2 & $20 \%$ \\
\hline TOTAL & 10 & $100 \%$ \\
\hline
\end{tabular}

Fonte: dados coletados das professoras. (2017)

Apesar que o aluno deve ser motivado a ler sozinho, de forma que envolva assuntos pertinentes a sociedade na qual ele está inserido e aos poucos vai compreendendo o sentido do texto que lê, tendo condições até de explica-lo, fazendo com que se torne uma criança que sabe ler entre linhas, é importante que o professor esteja direcionando essa leitura para que realmente sua aprendizagem seja adquirida.

A leitura é uma atividade que se realiza individualmente, mas que se insere num contexto social, envolvendo disposições atitudinais e capacidades que vão desde a decodificação do sistema de escrita até a compreensão e a produção de sentido para o texto lido. Abrange, pois, desde as capacidades desenvolvidas no processo de alfabetização "stricto sensu" até capacidades que habilitam à participação ativa nas práticas sociais letradas que contribuem para o seu letramento. (CARVALHO, 2006, p.21)

De acordo com Carvalho (2006, p. 21), mesmos utilizando os mais diversificados recursos pedagógicos, a aprendizagem da leitura acontece de forma individual, de acordo com a socialização e as 
atitudes do interesse e da capacidade em identificar e interpretar os sinais linguísticos que são as letras, associando-os aos sons de cada um que a criança desenvolve durante o estudo. A respeito das formas de se trabalhar com a leitura em sala de aula, têm-se os resultados apresentados na Tabela 4.

Tabela 4 - Quais as formas de se trabalhar com leitura em sala de aula?

\begin{tabular}{|l|c|c|}
\hline \multicolumn{1}{|c|}{ Respostas } & Prof. & \% \\
\hline Forma silenciosa individualmente & 2 & $20 \%$ \\
\hline $\begin{array}{l}\text { Em voz alta (individualmente ou em grupo) quando } \\
\text { fizer sentido dentro da atividade }\end{array}$ & 3 & $30 \%$ \\
\hline Através de rótulos e embalagens de produtos & 4 & $40 \%$ \\
\hline Recorte e colagem de letras e formação de & 1 & $10 \%$ \\
\hline palavras & $\mathbf{1 0}$ & $\mathbf{5 0 \%}$ \\
\hline
\end{tabular}

Fonte: dados coletados das professoras. (2017)

É importante que, a prática da leitura na Escola permita ao aluno o acesso ao mundo e as suas diversas formas de leitura e escrita, de forma significativa e quase de forma imperceptível. Quando o aluno percebe que já está lendo e interpretando e ainda escrevendo e falando corretamente é motivo de muita felicidade e demonstra uma sensação de liberdade. Mas, para que isso aconteça é necessário: "despertar na criança a noção de leitura como um processo abrangente de compreensão de sentido, fruto de diálogo com o que é lido. Algo muito vivo e desafiante, ao mesmo tempo, exigente e compensador". (MARTINS 1989, p.35)

Portanto, é importante que o professor busque métodos que faça a criança ter "noção de leitura", pois assim aos poucos vai se desenvolvendo o gosto de praticar a leitura e interpretação dos mais variados textos. Porém é necessário que se conheça as potencialidades e dificuldades de aprendizagem de cada aluno para adaptar o método de ensino e aprendizagem de acordo com as necessidades do mesmo de forma individual.

Ao ler silenciosamente, o aluno desenvolve o raciocínio lógico e a compreensão do texto, o que facilita ainda a interpretação do texto, sendo capaz de fazer o reconto daquilo que acabou de ler.

A leitura em grupo contribui para a socialização e a entonação de voz, ritmo e pontuação correta, e isso é imprescindível 
que o aluno compreenda desde os anos iniciais do Ensino Fundamental.

O trabalho com rótulos e embalagens de produtos, além de contribuir para o desenvolvimento do raciocínio, aumenta sua curiosidade e ao chegar em casa e supermercados terá vontade de ler tudo que ver escrito, e isso é fundamental para o aprendizado da criança.

O professor deve estar sempre atento ao comportamento do aluno em todos os momentos e principalmente na hora de leitura. Por isso, os mesmos foram questionados e os resultados apresentados na Tabela 5 .

Tabela 5 - Você acha que seus alunos se interessam pela leitura em sala de aula?

\begin{tabular}{|c|c|c|}
\hline Respostas & Prof. & \% \\
\hline $\begin{array}{c}\text { Sim, pois é uma novidade e ajuda na } \\
\text { concentração }\end{array}$ & 4 & $30 \%$ \\
\hline $\begin{array}{c}\text { As crianças estão na fase da descoberta e } \\
\text { tem sede conhecimento e para elas a leitura é uma } \\
\text { forma de diversão diversificada }\end{array}$ & 3 & $30 \%$ \\
\hline $\begin{array}{l}\text { Apenas uma pequena parte dos alunos se } \\
\text { dispersam brincando, demonstrando falta de } \\
\text { interesse, mas isso acontece porque não tem noção } \\
\text { de leitura e ainda precisam ser incentivados a } \\
\text { construir sua aprendizagem. }\end{array}$ & 3 & \\
\hline TOTAL & $\mathbf{1 0}$ & $\mathbf{1 0 0}$ \\
\hline
\end{tabular}

Fonte: dados coletados das professoras. (2017)

A leitura em sala de aula para o aluno é uma novidade para o mesmo, pois nessa fase a criança está descobrindo e tem muito interesse em aprender principalmente se as atividades de leitura acontecer de forma agradável e diversificada, porém alguns ainda estão imaturos e não se interessam pelo assunto e ficam brincando.

É importante que o aluno seja estimulado a construção do conhecimento da leitura, para que isso aconteça, o professor utiliza de estratégias criativas que é uma forma de aprender a leitura de forma lúdica e prazerosa, sendo capaz de desenvolver a leitura e a escrita ao mesmo tempo. 
A formação de crianças que gostem de ler precisa de muita dedicação do professor e dos pais, sempre as incentivando a construir seu conhecimento de leitura, demonstrando às mesmas a importância da compreensão da leitura para sua convivência em comunidade. Qualquer humano que não tenha suas faculdades danificadas é capaz de aprender a falar simplesmente pelo fato de estarem em interação com outros seres humanos e sem necessidade de um treinamento específico. (PEREIRA, 2004, p. 160).

É imprescindível que a criança tenha ajuda para a aquisição da leitura, tanto em seu ambiente familiar como escolar, através da socialização e interação com o outro e da incentivação que recebe de seus pais e do professor para que conquiste sua autonomia em aprender a ler.

A escola como formadora de seres pensantes é capaz de motivar o aluno a desenvolver a leitura de forma prazerosa, utilizando métodos e atividades pedagógicas que o levem a raciocinar com clareza, sempre de acordo com seus estágios desde o início da sua vivência escolar com seus colegas e profissionais da educação. Goodman (1995, p. 58) defende que:

O desenvolvimento dos processos de leitura e escrita iniciam-se antes mesmo da criança entrar na escola, ou seja, dentro da família e da comunidade. Nessas ocasiões a criança está sujeita a situações de leitura e escrita, iniciando seu contato com o sistema linguístico de seus pares. O estudo da leitura foi sistematizado por alguns autores em estágios, desde o aprendizado das primeiras letras até a compreensão de textos completos. (GOODMAN, 1995, p. 58)

De acordo coma a sua idade, a mente da criança está preparada para a construção de um tipo de ensinamento, que em seguida será corretamente ampliado tanto pelo professor como pelos pais, assim a mesma terá o conhecimento e muito sucesso na leitura e em todos os conteúdos curriculares. Portanto, o professor deve ser muito observador a fim de que perceba o momento certo de iniciar a 
leitura com seus alunos. Segundo Emília Ferreiro apud Goodman (1999, p. 58):

O desenvolvimento da leitura pode ser dividido em três estágios, que se processam em uma sequência de aquisições. O primeiro Estágio é o estágio no qual a criança começa a diferenciar os dois tipos de representação gráfica: o desenho e a escrita, é o primeiro passo para que elas aprendam o que é e o que não é lido. Esse processo começa quando elas percebem que a forma e a disposição das letras em nada lembram o objeto a que elas se referem (ao contrário do desenho). Tais aquisições são permanentes e tornar-se-ão mais complexas com o desenvolvimento da criança. $O$ segundo estágio é quando a criança passa a ter mais controle sobre as características qualitativas (letras diferentes) e quantitativas (quantidade de letras) de uma palavra, tornando-se mais capazes de perceber as diferenças entre vários termos escritos. Além disso, os critérios de determinação de significado tornam-se mais rígidos, ou seja, um grupo de letras não pode ser qualquer objeto, mas apenas um específico. O terceiro Estágio é quando a criança começa a utilizar o critério do "som", na escolha de letras em palavras, ou seja, para sons semelhantes letras semelhantes. Com essa descoberta a criança começa a entender a existência de uma ligação entre os sons e as palavras e aos poucos o processo de leitura vai mudando, tornando-se mais rápido e sintético. Na medida em que o processo se torna linear, há um progressivo desenvolvimento dos hábitos de leitura e da capacidade de compreensão de textos mais complexos.

A criança dos primeiros anos do ensino Fundamental desenvolve a aquisição da leitura primeiramente através do reconhecimento de desenhos comparando-os com as letras, e assim constrói o conhecimento das letras. Observando como as letras ficam em uma palavra, faz uma leitura oral, já sabendo diferenciar a quantidade de letras, as diferenças dos desenhos de cada uma delas, identifica os sons de cada uma, formar silabas, palavras e em seguida 
já começa a ler e essa etapa é um marco em sua vida. A Tabela 6 evidencia a importância da utilização da biblioteca como forma de incentivar a criança para a leitura.

Tabela 6 - Você considera importante o uso da Biblioteca escolar para incentivar o aluno a aprendizagem da leitura?

\begin{tabular}{|l|c|c|}
\hline Alternativas & Respostas & $\mathbf{\%}$ \\
\hline Sim & 10 & $100 \%$ \\
\hline Não & - & \\
\hline Talvez & - & \\
\hline TOTAL & $\mathbf{1 0}$ & $\mathbf{1 0 0} \%$ \\
\hline
\end{tabular}

Fonte: dados coletados das professoras. (2017)

Todos os profissionais entrevistados concordaram que o uso da Biblioteca escolar para incentivar o aluno a aprendizagem da leitura. Compreendeu-se que as crianças dos anos iniciais do Ensino Fundamental dentro da biblioteca se sente motivado com tantos livros e com isso desenvolve o gosto pela leitura, a curiosidade em saber o que está escrito em suas páginas e o entusiasmo pelos personagens e suas histórias, suas aventuras e tudo que se relaciona a eles.

A biblioteca escolar, sua organização, acervo e uso constituem-se talvez no testemunho mais real do efetivo compromisso da comunidade escolar com a educação e a cultura. Podemos considerá-la como o espaço da cultura dentro da escola, oportunizando e estimulando o contato e o convívio interativo entre os alunos, professores, pais e responsáveis, na mediação do conhecimento que trazem os livros, revistas, jornais e outras fontes de pesquisa e cultura. (SANTOS, 2005. p. 37).

É na biblioteca escolar que a criança desenvolve a leitura, pois se sente maravilhada com a organização e por ser um local em que se socializa e conhece as mais variadas culturas e ao interagir através da ajuda do professor aprende a ler de forma clara, sabendo apreciar as várias formas de ler e pesquisar na biblioteca. 
Sabe-se que existem várias formas de trabalhar o desenvolvimento da leitura com os alunos dos anos iniciais do Ensino Fundamental, e é muito importante que os professores utilizem todos os recursos possíveis de forma criativa, para que as crianças se sintam motivadas a construir seu conhecimento em leitura.

A criança necessita ser incentivada a conquistar o seu próprio conhecimento de acordo com suas especificidades e sua forma de reconhecer os sons através dos símbolos que são as letras, gravuras e desenhos criados por ele mesmo. "O processo de ler é complexo. Trazer à mente uma informação necessária, aplicar algum conhecimento a uma situação nova, o engajamento de muitos fatores é essencial se queremos fazer sentido do texto" (KLEIMAN, 2001, p. $13)$.

No entanto para que isso dê resultados se faz necessário que a criança seja motivada desde pequena para que a aquisição da leitura não se torne limitada, restrita somente a sala de aula.

A escola é uma Instituição que tem várias responsabilidades para com o aluno e aqui se destaca a história aquisição da leitura. A maioria das crianças quando ingressa na escola já tem uma noção básica do que é leitura e a escrita, devido ao contato com livros, revistas e leituras que estão por todos os lados na sociedade em que vivem principalmente no seio familiar, onde os pais leem histórias, contos de fadas para eles em sua casa. A respeito dos principais recursos utilizados em sala de aula é apresentada a Tabela 7.

Tabela 7 - Marque os principais recursos utilizados em sala de aula que contribuem para o desenvolvimento leitura?

\begin{tabular}{|c|c|c|}
\hline Alternativas & Respostas & \% \\
\hline Jogos & 4 & $40 \%$ \\
\hline Revistas & 3 & $30 \%$ \\
\hline Livro didático & 2 & $20 \%$ \\
\hline $\begin{array}{c}\text { Textos } \\
\text { informativos }\end{array}$ & 1 & $10 \%$ \\
\hline TOTAL & $\mathbf{1 0}$ & $\mathbf{1 0 0 \%}$ \\
\hline
\end{tabular}

Fonte: dados coletados das professoras. (2017)

Educação In Loco, v.01, n. 01, jan.-jun. 2020 - ISSN 2675-4304 
O quadro acima demonstra que os professores utilizam jogos, revistas, e textos informativos como recursos que contribuem com o desenvolvimento da leitura. Sabe-se que os jogos são importantes no desenvolvimento da criatividade e dos conhecimentos dos sons e letras para a formação das palavras. A utilização de revistas através de recortes de letras, palavras e de gravuras também contribuem para que a criança adquira seu gosto pela leitura, já os textos informativos são necessários para aumentar a curiosidade em conhecer ainda mais a leitura e saber de tudo que acontece.

Quanto mais variado é esse material, mais adequado para realizar diversas atividades de exploração, classificação, busca de semelhanças ou diferenças e para que o professor, ao lê-los em voz alta, dê informações sobre "o que se pode esperar de um texto" em função da categorização do objeto que o veicula. Insisto: a veracidade de materiais não só é recomendável (melhor dizendo, indispensável) no meio rural, mas em qualquer lugar onde se realize uma ação alfabetizadora. Ferreiro (1997, p. 33).

De acordo com a autora é importante que o professor tenha criatividade em utilizar vários materiais para que o aluno possa explorar, manusear, comparar e realizar sua alfabetização. É recomendável que também sejam utilizados os meios de comunicação como rádios, televisão, dentre outros que a comunidade, a qual a criança faz parte, tem acesso. Quanto ao fator da aprendizagem da leitura dos alunos, tem-se os resultados apresentados na Tabela 8 .

Tabela 8 - Como você explica a aprendizagem da leitura pelos alunos?

\begin{tabular}{|c|c|c|}
\hline Respostas & Prof. & \% \\
\hline $\begin{array}{c}\text { É uma realização pessoal em que a } \\
\text { criança aprende a ler e interpretar }\end{array}$ & 3 & $30 \%$ \\
\hline $\begin{array}{c}\text { A leitura acontece quando o aluno } \\
\text { desenvolve a percepção de sons e letras } \\
\text { conseguindo fazer a junção e compreender o que } \\
\text { está escrito }\end{array}$ & 3 & $30 \%$ \\
\hline $\begin{array}{c}\text { Esse processo pode acontecer de acordo } \\
\text { com as práticas de leitura, a curiosidade do aluno e }\end{array}$ & 4 & $40 \%$ \\
\hline
\end{tabular}

Educação In Loco, v.01, n. 01, jan.-jun. 2020 - ISSN 2675-4304 
a motivação que ele recebe

TOTAL

Fonte: dados coletados das professoras. (2017)

Pode-se dizer que a aprendizagem da leitura acontece de acordo com os recursos metodológicos utilizados em sala de aula e a dedicação do aluno e de seus pais em casa, no sentido de estar sempre colaborando para que esse conhecimento se desenvolva.

O conhecimento atualmente disponível a respeito do processo de leitura indica que não se deve ensinar a ler por meio de práticas centradas na decodificação. Ao contrário, é preciso oferecer aos alunos inúmeras oportunidades de aprenderem a ler usando os procedimentos que os bons leitores utilizam. É preciso que antecipem, que façam inferências a partir do contexto ou do conhecimento prévio que possuem, que verifiquem suas suposições - tanto em relação à escrita, propriamente, quanto ao significado. É disso que se está falando quando se diz que é preciso "aprender a ler, lendo": de adquirir o conhecimento da correspondência fonográfica, de compreender a natureza e o funcionamento do sistema alfabético, dentro de uma prática ampla de leitura. Para aprender a ler, é preciso que o aluno se defronte com os escritos que utilizaria se soubesse mesmo ler - com os textos de verdade, portanto. (BRASIL, 1997, p.55-56)

O início do saber ler pode acontecer nos primeiros anos do Ensino Fundamental e lentamente vai ficando cada vez mais fluente, de acordo com o incentivo que a criança recebe tanto em casa como na escola. Os hábitos de ler, escrever, dentre outros estão relacionados aos processos motivacionais, que contribuem para a construção do conhecimento da criança. Assim a criança começa a leitura com atividades motivadoras que a interesse, mas que só mais tarde perceberá quantos benefícios tais atividades lhe trarão para a vida em sociedade e também para a aquisição de outras aprendizagens.

Para que o aluno construa sua aprendizagem da leitura, além de motivá-lo a querer aprender, o professor precisa respeitar suas

Educação In Loco, v.01, n. 01, jan.-jun. 2020 - ISSN 2675-4304 
habilidades e competências cognitivas, para que o mesmo não fique frustrado. Pois todos precisam saber pensar para construir o seu conhecimento, e cada um tem suas limitações e suas habilidades que precisam ser desenvolvidas com o passar do tempo e com atividades que se propõe a isso

A motivação é a principal aliada às capacidades comportamentais do ser humano para que tenha sucesso, por isso é de suma importância que a família em parceria com a escola motive a criança para que a sua aprendizagem aconteça.

Motivação é um tema da psicologia que estuda as razões pelas quais o homem se comporta de uma determinada forma. A motivação é aquilo que impulsiona um comportamento, o qual está dirigido a um objetivo específico, não é algo que possa ser diretamente observado; inferimos a existência de motivação observando um comportamento. (BRAGHIROLLI et al, 1990, p. 90).

Baseado na citação acima se pode dizer que a criança precisa ser impulsionada a aprender a ler, porém não se percebe quando uma pessoa está motivada, mas pode presenciar o resultado da motivação a partir do momento que o aluno desperta para a leitura e faz isso sozinho. Ao aprender a ler, ele fica um pouco individualista, mas também se socializa, só demonstra que não precisa tanto de ajuda. A respeito da contribuição da família para a construção do conhecimento da leitura dos filhos, tem-se os resultados evidenciados na Tabela 9.

Tabela 9 - Como a família contribui para a construção do conhecimento da leitura dos filhos?

\begin{tabular}{|c|c|c|}
\hline Alternativas & Prof. & \% \\
\hline $\begin{array}{c}\text { Lendo historinhas para seus filhos, contar } \\
\text { contos de fadas }\end{array}$ & 2 & $40 \%$ \\
\hline $\begin{array}{c}\text { É importante que as crianças sejam } \\
\text { incentivadas pelos pais a manusearem livros, } \\
\text { jornais, revistas, panfletos }\end{array}$ & 1 & $10 \%$ \\
\hline $\begin{array}{l}\text { Elogiar o filho a cada acerto e corrigi-lo } \\
\text { sempre que necessário }\end{array}$ & 3 & $30 \%$ \\
\hline Ser paciente ao ajudar a criança em casa, & & \\
\hline
\end{tabular}

Educação In Loco, v.01, n. 01, jan.-jun. 2020 - ISSN 2675-4304 


\begin{tabular}{|l|l|l|}
\hline $\begin{array}{l}\text { pois ela não tem ideia do que seja aqueles } \\
\text { risquinhos que são as letras. }\end{array}$ & & \\
\hline TOTAL & $\mathbf{1 0}$ & $\mathbf{1 0 0 \%}$ \\
\hline
\end{tabular}

Fonte: dados coletados das professoras. (2017)

"É importante que os pais leiam historinhas para seus filhos, deixem que manuseiem livros, revistas, jornais e panfletos, mostrar para a criança que as letras possuem sons, fazer com que ela perceba a escrita e os sons das palavras, elogiando o filho a cada acerto e corrigi-lo sempre que necessário, sendo paciente ao ajudar a criança em casa, pois ela não tem ideia do que seja aqueles risquinhos que são as letras." (ENTREVISTADOS, 2017)

Desde os antepassados as crianças ouvem as histórias lidas pelos pais e/ou familiares, e já observam as letras que no início são apenas símbolos. Só com o passar do tempo é que percebem, através de comparações dos desenhos ou rabiscos que veem nas leituras, as letras. Ferreiro (1990, p. 45) afirma que "aprender a ler começa com o desenvolvimento da língua escrita". A criança vê a escrita e consegue juntar os sons, as letras e adquirir sua leitura. Por isso a importância de deixar que a criança esteja sempre em contato com a escrita, manuseando livros, revistas e outros tipos de escrita.

A criança é muito observadora e com seus olhinhos brilhando fica atenta para compreender como as pessoas falam. Depois as imita e constrói seu próprio conceito a respeito da língua falada em relação à escrita. Porém, cada criança tem seu ritmo cognitivo. É importante que construa uma aprendizagem de forma prazerosa, através de atividades saudáveis, criativas, se espelhando na postura do professor, num ambiente ao ar livre, observando a natureza, que é um espaço tranquilo para as crianças de diferentes idades conviverem e se socializarem.

De acordo com Piaget (1978), apud SILVEIRA, (2006, p.161): "a evolução da lógica e da moral pode ser resumida em quatro estágios de desenvolvimento mental: Período Sensório-motor (0 a 2 anos): Piaget usa a expressão "a passagem do caos ao cosmo" para traduzir o que o estudo sobre a construção do real, descreve e explica.

Educação In Loco, v.01, n. 01, jan.-jun. 2020 - ISSN 2675-4304 
De acordo com a tese piagetiana, "a criança nasce em um universo para ela caótico, habitado por objetos evanescentes com tempo e espaço subjetivamente sentidos, e causalidade reduzida ao poder das ações, em uma forma de onipotência". No recém-nascido, portanto, as funções mentais limitam-se ao exercício dos aparelhos reflexos inatos. Período pré-operatório ( 2 a 7 anos): para Piaget, o que marca a passagem do período sensório-motor para o préoperatório é o aparecimento da função simbólica ou semiótica, ou seja, é a emergência da linguagem. Nessa concepção, a inteligência é anterior à emergência da linguagem e por isso mesmo "não se pode atribuir à linguagem a origem da lógica, que constitui o núcleo do pensamento racional". Período das operações concretas (7 a 11, 12 anos): neste período o egocentrismo intelectual e social (incapacidade de se colocar no ponto de vista de outros) que caracteriza a fase anterior dá lugar à emergência da capacidade da criança de estabelecer relações e coordenar pontos de vista diferentes (próprios e de outrem) e de integrá-los de modo lógico e coerente.

Outro aspecto neste estágio é a capacidade da criança de interiorizar as ações e realizar operações mentalmente. Período das operações formais (12 anos em diante): a criança amplia as capacidades conquistadas na fase anterior, já consegue raciocinar sobre hipóteses na medida em que ela é capaz de formar esquemas conceituais abstratos e através deles executar operações mentais dentro de princípios da lógica formal. (PIAGET, 1978, apud SILVEIRA, 2006, p.161)

Há o estágio em que a criança desenvolve o gosto pela leitura e toda palavra que vê, quer ler, quer saber por que é escrito assim, o que significa e, questionando aprende a leitura e descobre as formas das letras, das figuras, das imagens e identifica os sons.

As capacidades analisadas são partes componentes da capacidade de fazer uma ligação simbólica entre sons e letras do alfabeto. A primeira é a capacidade de compreender a ligação simbólica entre letras e sons da 
fala. A segunda é a capacidade de enxergar as distinções entre as letras. A terceira é a capacidade de ouvir e ter consciência dos sons da fala com suas distinções relevantes da fala. (LEME. 1994, p.9)

Essas capacidades vão aumentando de acordo a história da leitura nos primeiros anos do Ensino Fundamental através da motivação que a criança recebe tanto de seus familiares como de seu professor e colegas, pois ao se socializarem, trocam experiências que servirão de modelo para a aquisição da leitura, além de contribuírem para que outras aprendizagens aconteçam.

Em casa principalmente, a criança deve ter uma boa orientação e desfrutar de convivência harmoniosa e saudável com todos os familiares, pois é com eles, normalmente, que a mesma desenvolve a segurança necessária para a construção de uma aprendizagem sólida desde o jardim de infância.

$\mathrm{Na}$ Tabela 10 buscou-se saber dos professores entrevistados como os mesmos trabalha a leitura em sala de aula, cuidando para que os mesmos não fiquem cansados? Suas respostas estão expostas na tabela e comentadas abaixo.

Tabela 10 - Como você trabalha a leitura em sala de aula, cuidando para que os mesmos não fiquem cansados?

\begin{tabular}{|c|c|c|}
\hline Respostas & Prof. & $\mathbf{\%}$ \\
\hline $\begin{array}{c}\text { Com respeito a individualidade e a } \\
\text { capacidade de aprendizagem de cada aluno e de } \\
\text { acordo com as etapas do seu desenvolvimento }\end{array}$ & 3 & $30 \%$ \\
\hline $\begin{array}{c}\text { Observando o ritmo de construção do } \\
\text { conhecimento da leitura de forma individual. }\end{array}$ & 2 & $20 \%$ \\
\hline $\begin{array}{c}\text { Utilizando métodos que façam a criança } \\
\text { raciocinar e refletir sobre o que está lendo. }\end{array}$ & 3 & $30 \%$ \\
\hline $\begin{array}{c}\text { Agindo com afetividade, para que o aluno } \\
\text { desperte o desejo e o gosto pela leitura e a escrita }\end{array}$ & 2 & $20 \%$ \\
\hline TOTAL & $\mathbf{1 0}$ & $\mathbf{1 0 0 \%}$ \\
\hline
\end{tabular}

Fonte: dados coletados das professoras. (2017)

É de fundamental importância a aquisição da leitura pela criança nos primeiros anos do Ensino Fundamental, pois é nessa fase que se encerra uma etapa importante para todas as conquistas 
educacionais, que serão a base para uma aprendizagem sólida para a sua vida.

O professor deve ter respeito pela individualidade de cada aluno e com as etapas do seu desenvolvimento, tendo o cuidado em sempre observar seu ritmo de construção do conhecimento da leitura, obtendo, assim um bom resultado na organização do seu corpo físico, mental e cognitivo a fim de que o mesmo possa adquirir prazerosamente hábitos de leitura. Alves (2004, p.11) ressalta, entretanto que: "há necessidade e importância de intercalar momentos de reflexão no ato da leitura, pois do contrário poderia ocorrer um processo de destruição do pensamento. Porque o hábito de ler deve ser caracterizado pelo prazer e não pela quantidade de livros lidos".

Portanto, não se pode pressionar a criança na aquisição da leitura, pois ela precisa sentir gosto para realização de tal atividade. Quando a criança apresenta comportamentos que demonstram já estar preparada para a aquisição da leitura, o professor deve intervir com atividades pedagógicas que contribuam com a construção do conhecimento de seu aluno.

É compreensível que o aluno apresentar alguma dificuldade de aprendizagem na leitura nos primeiros anos do Ensino Fundamental. Quando esse problema surgir, se propõe buscar ajuda psicológica ou psicopedagogia que possibilite esclarecimento de como lidar com a suposta situação ou o acompanhamento a fim de conseguir o encaminhamento dessas dificuldades, assim a criança poderá construir seu conhecimento.

É claro que além dos conhecimentos básicos, o alfabetizador precisa de outros dons básicos para se sair bem. "Ele deve ter respeito pelos alunos, evitar o papel de cúmplice de um sistema interessado em manter esmagada uma grande parte de seu povo, confiar na capacidade de desenvolvimento dos alunos e ter criatividade, invencibilidade, iniciativa, combatividade e fé em sua capacidade de tornar este mundo melhor. (LEMLE, 1994, p. 69). 
O aluno pode demonstrar ao professor aquilo que já sabe ler, ficando mais fácil de receber ajuda se por acaso o mesmo tiver alguma dificuldade, para que assim, possa construir rapidamente seu conhecimento.

Sabe-se que há aqueles que agem de forma diferente, sentemse envergonhados por suas dificuldades e não gostam muito de serem ajudados. O seu silêncio é uma forma de colocar uma barreira entre ela, seus professores e colegas. Além de tentar afastar a dificuldade, evitando a baixa autoestima. É necessário que se faça um trabalho de conscientização, socialização e inteiração com todas as crianças para que aconteça a aquisição da leitura, para o seu crescimento e sua aprendizagem. A aquisição da base ortográfica envolve aspectos afetivos, sociais, culturais, lógicos, perceptivos, motores, para que a aprendizagem seja de fato construtiva.

Para Ferreiro (1999, p.213), quando o meio não provê esta informação, falha uma das ocasiões de conflito. Por isso vemos crianças chegarem até o nível da aprendizagem das sílabas, mas não, além disso. Portanto, é imprescindível que o professor tenha criatividade para trabalhar com esses alunos de forma que se desenvolva, lendo e compreendendo a frase e/ou texto.

A aquisição da leitura surge de maneira espontânea nas crianças com aproximadamente três anos de idade. Nessa fase, o que pensam e elaboram sobre a leitura convencional, é que uma figura pode ser lida e interpretada, além disso, para lê-las são necessárias gravuras conhecidas e de formato maior e se possível legíveis, para que possam construir sua leitura sobre aquilo que seus olhos veem e seu raciocínio compreende.

Quando querem ler, inventam suas próprias palavras e textos, observam gravuras e brinquedos, colocam nomes que surgem em sua imaginação, demonstram que podem ler. Acreditam que palavras com menos de três letras ou letras repetidas não podem ser lidas. Acreditam também, durante o processo, que uma letra basta para registrar uma emissão sonora. Ainda, em dado momento de conflito, enxertam letras para aumentar a palavra considerada pequena demais para dar conta do seu significado. 
Alguns fatores influenciam a aquisição do conhecimento da leitura que são muito importantes o professor se preparar com atividades pedagógicas a fim de que a aprendizagem da leitura aconteça de forma concreta e para a vida toda. De acordo com Silveira (2006, p.96), os fatores que influenciam no desenvolvimento da capacidade de aprender são:

Querer e aprender: desenvolver no aluno o aprendizado dos verbos querer e aprender, de modo a motivá-los para que eles sejam conjugados da seguinte maneira: Eu quero aprender. Esse comportamento exigirá dos alunos uma série de atitudes, destacando-se interesse, motivação, atenção, compreensão, participação e expectativa de aprender a conhecer, a fazer, a conviver e a tornar-se uma pessoa. Respeitar as competências e habilidades: desenvolvimento de aptidões cognitivas e procedimentais. Quem aprende a ser competente, desenvolve um interesse especial por aprender. No entanto, só desenvolvemos a capacidade de aprender quando aprendemos a pensar. Só pensamos bem quando aprendemos métodos e técnicas de estudo. É esse fator que garante a capacidade de autoaprendizagem do aluno. Aprendizagem de conhecimentos ou conteúdo: a construção de um currículo escolar, com disciplinas atualizadas e bem planificadas, é fundamental para que o aluno desenvolva sua compreensão a respeito do ambiente natural e social, do sistema político, da tecnologia, das artes e dos valores em que se fundamenta a sociedade, conforme o que determina o artigo 32 da Lei de Diretrizes Bases da Educação Nacional (LDB). (SILVEIRA, 2006, p.96),

$\mathrm{O}$ querer aprender a ler precisa ser estimulado pelo professor em alguns alunos. Percebe-se que aprender a ler depende da vontade do aluno e da motivação do professor com estratégias animadoras que conquistem a confiança do aluno para que ele consiga gostar de aprender.

\section{Considerações Finais}

Educação In Loco, v.01, n. 01, jan.-jun. 2020 - ISSN 2675-4304 
Os principais resultados evidenciaram que a importância da leitura está na socialização dos estudantes, por meio da prática da leitura, em voz alta (individualmente ou em grupo), utilização de jogos e revistas, alavancada pelo interesse das crianças por meio de descobertas, gerando um aprendizado pela curiosidade e motivação. Em abordagem complementar foi possível apresentar as inferências a seguir.

Compreendeu-se que a leitura, quando estimulada, incentivada e bem orientada contribui para a formação de um adulto capaz de viver em sociedade, contribuindo para o desenvolvimento integral do educando. A leitura trabalhada de forma mais atrativa, ampla e próxima à realidade dos alunos, contribui para aflorar nos mesmos, o gosto e o hábito da prática da leitura sendo um processo gradativo, contribuirá para a formação de um cidadão letrado.

Dessa forma, entende-se que é fundamental na alfabetização, que a leitura seja trabalhada de forma significativa, a partir dos diversos tipos de materiais textuais presentes no contexto social, ou seja, com materiais diversificados, para que os alunos se aproximem da leitura, e tomem gosto desde a menor idade desta prática que é vital para o seu desenvolvimento futuro.

É natural e desejável pensarmos que, por ser um elemento básico do ensino, a prática da leitura seja exercida sem complicações. Contudo, isso não expressa a realidade vivenciada nos espaços escolares onde se observa momento de crise com relação à formação de leitores.

A leitura pode ser considerada um meio imprescindível para a conscientização e construção de saberes necessários a uma vida digna dentro da sociedade. Para que isso aconteça é importante que o professor busque estratégias para que todas as crianças tenham o pleno desenvolvimento da leitura e da escrita, não fazendo da leitura uma prática constante apenas na alfabetização e nas séries iniciais, mas uma prática diária em todas as fases da vida escolar.

A leitura e a escrita apresentam características que fazem surgir preocupação com a língua e a prática pedagógica e por isso, o 
professor precisa trabalhar o aluno para que o mesmo possa aproveitar o máximo possível, mas também é necessário ter cuidado com as formas e práticas de produção da leitura e da maneira pela qual o mesmo a constrói, deixando que o aluno exponha suas ideias e curiosidades para que em grupo discutam e compreendam as formas de falar e escrever sempre de acordo com a cultura de cada um.

E assim a criança desenvolve, através da motivação, da afetividade, carinho e compreensão do professor juntamente com o apoio de sua família, o gosto e as habilidades necessárias para construir seu conhecimento literário, bem como a interpretação e a escrita nos anos iniciais do Ensino Fundamental.

\section{Referências}

ALVES, R. Ao professor, com o meu carinho. Campinas, São Paulo: Verus Editora, 2004, p.11

BRAGHIROLLI, E. M. et al. Psicologia Geral. $9^{\mathrm{a}}$ ed. Porto Alegre: Editora Vozes, 1990.

BRASIL. CAMARA BRASILEIRA DO LIVRO - CBL. 2001, p.90. BRASIL. Secretaria de Educação fundamental. Parâmetros Curriculares Nacionais: Língua Portuguesa. - Brasília: 1997. P.55 - 56

CARVALHO, Maria Angélica Freire. Prática de leitura e escrita. Brasília: Ministério da educação, 2006, p. 21.

FERREIRO, Emília. PALÁCIO, Margarida Gomes. Os processos de leitura e escrita: novas perspectivas. Trad. Luiza Maria Silveira. Porto Alegre: Artes Médicas, 1990, p.33, 45, 58

FERREIRO, Emília \& TEBEROSKY, Ana. Psicogênese da língua escrita. Porto Alegre: Artes Médicas, 1999, p.213

GADOTTI, Moacir e BRANDÃO, José (orgs.). Educação: teoria, prática e proposta. 9. ed. São Paulo: Cortez: Instituto Paulo Freire, 2001, p. 27

KLEIMAN, Â. Leitura: Ensino e pesquisa. Campinas SP: Pontes, $2^{\mathrm{a}}$ Ed, 2001, p. 13.

LEMLE. Mirian. Guia Teórico do Alfabetizador. Editora Ática. $8^{\mathrm{a}}$ edição. São Paulo. 1994, p. 9, 69 
MARTINS, Maria Helena. O que é leitura. São Paulo: Brasiliense, 2006, p. 35

PIAGET, J.A formação do símbolo na criança: imitação, jogo e sonho, imagem e representação. Rio de Janeiro: Casa das Palmeiras. Rio de Janeiro, 2006.

ROSA, Guimarães. Grande sertão: veredas. Rio de Janeiro: José Olympio, 1956, p. 271

SMITH, Frank. O Letramento na educação escolar: desfazendo alguns mitos. In: DE CARVALHO, Maria Angélica Freire. Prática de leitura e escrita. Brasília: Ministério da educação, 2006, p. 36 SOARES, Magda. A escolarização da literatura infantil e juvenil. In: EVANGELISTA, Aracy Alves Martins; BRANDÃO, Helina Maria Brina; MACHADO, Maria Zélia Versiani (Org.). A escolarização da leitura literária: o jogo do livro infantil e juvenil. Belo Horizonte: Autêntica, 1999, p.19 